\title{
HERMENÉUTICA AFORÍSTICA
}

\author{
Andrés ORTIZ-OSÉS \\ Universidad de Deusto-Bilbao
}

\begin{abstract}
Resumen. Entiendo la Hermenéutica aforística como un logos intercalado entre los miembros disjuntos de la realidad vivida: buscando la articulación de la escisión y la sutura de la fisura: la mediación entre las raíces y las alas, entre el tiempo y el ser. Si la Hermenéutica trata de interpretar un texto o textura significativa, la Hermenéutica aforística trata de ofrecer el contexto humano del sentido: la aferencia de la referencia, los accidentes que encarnan el ser, los márgenes de la significación, la surrealidad de lo real. Una Hermenéutica aforística es por lo tanto una filosofia sensible, un lenguaje sensible a la experiencia de la vida y a las vivencias de la existencia, capaz de auscultar ciertas claves sutiles de nuestro mundo en devenir.
\end{abstract}

Aforismo significa delimitación o definición aguda, así como elección/selección (de aforidso = delimitar y seleccionar), aunque yo empalmaría la etimología de nuestros propios afos con "aforao", en la cosignificación de divisar o considerar (aforar). O los aforismos como consideraciones pregnantes en cuanto foros o aforos de significación humana, máximas mínimas que condensan la evaluación de la realidad a modo de "breverías". Pues bien, cabría ubicar esta evaluación en una visión del mundo de carácter estoico-epicúreo y de signo cristianoescéptico, bajo cuyos nombres se mienta una actitud abierta y asuntiva, es decir, coimplicativa o coimplicacional basada en una razón sensible a las junturas y transiciones del ser, a las mediaciones o remediaciones posibles, y en definitiva a la correlacionalidad de lo real. Se trata entonces de una Hermenéutica simbólica por cuanto interpreta el ser a través del sentido, situándose en el actual horizonte posmoderno aunque de modo autónomo. En efecto, prefiero el término de intramodernidad al de posmodernidad, ya que aquél plantea el Leit-motiv del sentido y no el Light-motiv de su volatilización. En todo caso, se trata de la propia maniera y el propio manierismo. 
Propugno aquí de nuevo una filosofia de la implicación, palabro que mienta el embarazo y lo embarazoso (implicatus) de una situación como la nuestra, pues una tal filosofía concibe la realidad en cuanto embarazada de sentido y sinsentido. Ahora bien, en cuanto embarazada de sentido, la realidad dice pregnancia simbólica, pero en cuanto embarazada de sinsentido, la realidad resulta embarazosa; finalmente la realidad desembarazada resulta desimpregnada y desimbolizada (nihilismo). Pero se trata de afirmar el sentido y asumir el sinsentido, lo cual produce una inevitable melancolía crítica que tiñe nuestro pensamiento así afectado. La filosofía así afectada asume el defecto como parte del afecto, así como la nada cual parte/partición del ser, del mismo modo a como el desamor comparte el amor y el silencio el ruido. Por eso nuestra última palabra es la coimplicación de los contrarios, la cual encuentra precisamente en esta aforística su lenguaje simbólico pertinente.

Pero para coimplicar los contrarios se precisa una actitud de libración o liberación a modo de oscilación entre ellos, basada en el libramiento o liberamiento de su carácter absoluto a través de su correlativación. Nuestro filósofo anglohispano G. Santayana expresó así este espíritu de libramiento o libración de cosas, cosificaciones y relaciones reificadas: «Me resisto al contagio humano, salvo provisionalmente, en la superficie, $y$ en asuntos que me son indiferentes: pero nunca de modo que, en el fondo, suponga renuncia a mi independencia" (Autobiografia). Se trata de cierto espíritu anarcoidallanarcordial compresente también en nuestra aforística, espíritu que requiere sin duda la asunción de cierta soledad (compartida): pues el sentido es anímico y cohabita el interior humano.

Así que en mi Aforística hay una afirmación dionisiana o vital, un sí a la vida contrapunteado apolíneamente por cierta retranca o introversión. De esta guisa trato de dialectizar la carne y el espíritu en el medio del alma, cohabitada por el amor: a la vez secular y sagrado, eros y ágape mediados por la filía o amistad, la cual refracta una libertad religada. A estas alturas de la vida uno celebra con nostalgia el pacto renacentista realizado entre Sócrates y Jesús, socratismo cristiano cuya clave simbólica está en concebir la existencia humana como un proceso de sublimación de los sentidos, o si se prefiere, como la apertura radical del tiempo al trastiempo, de la finitud a la infinitud y del sinsentido al sentido: lo cual es sin duda una forma de contentamiento basado en la asunción de una realidad interpretada simbólicamente. 
La sensificación de esta visión socrático-cristiana del mundo es el propio lenguaje aforístico, entendido como un decir no directo o en bruto sino transversal y en oblicuo (indirecto). El lenguaje aforístico no reprime lo vital pero lo represa, no retiene la vida pero la contiene, no la expone sino que la expresa. La contención define al lenguaje aforístico a pesar de su plurimorfía, ya que se autoconcibe como ascesis verbal: la misma contención o ascesis que sirve a la vida no para oprimirse sino para encauzarse, no para disecarse sino para canalizar su potencia.

Porque la vida es potencia (posse), cuyo arquetipo es el Dios de Nicolás de Cusa concebido neoplatónicamente como Potencia, Posibilidad o Poder-ser fundacional (Posse). En nuestra Hermenéutica simbólica hay que repensar ya no el ser clásico sino el pre-ser, ya no el Dios oficial sino el proto-Dios, ya no el poder sino la Potencia. El ser ya no es lo que es sino lo que puede ser, Dios ya no es el que es sino el que puede/pueda ser, la realidad no es simplemente sino complicadamente, la inmanencia no está dada sino trascendida. Ahora bien, se trata de una trascendencia inmanente, ya que la Potencia que inhabita al universo lo hace ser y realiza la realidad, la cual se funda/funde en la emergencia de dicha potencia. De este modo todo participa del mismo principio de "omnipotencia", el cual posibilita la omnipatencia de las cosas: lo que equivale a decir que el pulular de los seres es como una pluralidad de aforismos que proceden del libre fuero o potencial humano (humanado), configurando en su aforo o articulación el foro propio de las cosas entrevistas por el hombre en tanto intérprete del mundo.

Pero si esto es así, o sea, si la potencia precede o funda al ser, entonces el ser se retrotrae a su potencialidad como Dios a la nada desde la que creó y lo real a lo surreal que lo concrea. El sí occidental a la vida se asoma ahora abismáticamente al no oriental de la muerte, como la actualidad a la posibilidad y el lenguaje al silencio: la propia aforística comparece entonces como la coimplicación de contrastes que dan al traste con la vieja visión del ente como un trasto. Y, en efecto, los entes aforísticamente interpretados no son trastes sino contrastes, no son trastos sino trasgos, rasgos o trasuntos de un ser potencialmente relacional.

Curiosamente el misticismo neoplatónico de inspiración oriental sirve de fondo al radicalismo occidental y su nihilismo. Por eso la visión crítica que A. García Calvo mantiene contra la Realidad provendría del misticismo orientalizante, para el cual la negación antecede a la afirmación como el no-ser al ser y la 
nada al ente (nibil metafísico). Lo que pasa es que en nuestra propia concepción se trataría de coimplicar dualécticamente ser y no-ser, realidad y nada, vida y muerte (a ello denominamos coimplicacionismo simbólico, en cuyo contexto el propio nihilismo sólo se entiende como nihilismo simbólico y no político, anarcoidal y no anárquico, liberador y no libertario, culturalmente radical y no ácrata o extremista). En nuestro nihilismo simbólico cabe concebir a Dios como la Mismidad de todos los seres, la cual comparecería en la Muerte en cuanto «enmismamiento" final de todas las cosas en su in/definitud definitiva. Un tal Dios personifica la democracia hermenéutica que a todos nos iguala, de acuerdo con la autodefinición divina en $\mathrm{N}$. Cusa como la Igualdad de los contrarios.

\section{I. (Raíces y alas)}

0 . La verdadera naturaleza humana se extiende entre estos dos extremos complementarios, la garra y el ala, pero es ese intermedio el que hay que llenar de sustancia: esa zona intermedia en que la realidad toma cuerpo espiritual —psicológico, si se quiere-, y abolida la cual no quedan sino raíces o alas, lo infra y lo superhumano (J. Gil-Albert).

1. El mar cada verano está más lejos (José G. Nieto): la nieve cada invierno más adentro.

2. Me duele el mundo como un miembro desmembrado: a remembrar.

3. La belleza del mar cuando recibe el ocaso en su regazo: la puesta de sol en la mar apuesta.

4. En su poemario El arrabal, José G. Nieto pide a Dios que le mienta y engañe al final de sus días: Dios como transfigurador de la realidad humana.

5. Las religiones se han pasado toda la vida hablando de dioses que no aparecen por ninguna parte: sus huellas estarían holladas por las propias religiones.

6. Es hermosa la vida si el corazón la anida: es hermosa la vida cuando el alma la anima.

7. En tu aliento se configuran mis palabras: Nel vostro fiato son le mie parole (Miguel Ángel): la palabra del corazón como aliento cristalizado.

8. Para Nietzsche el Dios judeocristiano no es sólo el del Nuevo Testamento (rococó anímico): también el del Antiguo Testamento (terrible).

9. La fe en Dios, según T. Mann, es la fe en el amor, en la vida y en el arte: porque Dios simboliza el símbolo (el simbolismo). 
10. En T. Mann lucha el Espíritu paterno con la vida y el amor: aquel representa el deber protestante, pero este simboliza la gracia y la salvación.

11. La garra agarra agarrotadamente: el ala alea aleatoriamente.

12. La muerte no es el final: es el principio del fin.

13. Gala asumió la locura de Dalí: y Dalí la locura de Gala.

14. En cierta tradición medieval la mujer es diablesca: luego el diablo era femenino.

15. No hacer nada sin el obispo, dice la tradición: y nada que hacer con el obispo, dice la posmodernidad.

16. Dios es una creación humana: que mienta su propia creación.

17. Las lágrimas y su acuoso humor salado remiten al mar: aferentemente.

18. Comprender es integrar lo que se odia (T. Mann).

19. Observo a un grupo de hormigas comiendo a un abejorro aún vivo: acabo con verdugos y víctima para que no sufra.

20. Ayer se hablaba del sentido alegremente, hoy se habla del sinsentido alegremente: modas y modismos.

21. Ofrecer sentido a los demás: así me lo doy a mí mismo.

22. Abrirse a la vida: así se nos abre la vida.

23. La civilización perfecciona la barbarie (Voltaire).

24. La escritura como compensación: por eso la escritura serena de GilAlbert compensa su falta de serenidad (según el propio autor).

25. Para la salud espiritual los santos sacramentos: para la salud corporal los santos medicamentos: y para la salud anímica las santas meditaciones.

26. Mola no mola: el General nos amoló aunque se inmoló.

27. El ser aristotélico es sustancial (racional): el ser hermenéutico es sustancioso (simbólico).

28. Verdades como puños: la verdad ha tenido que ver con el puño (y sus puñetazos).

29. El hombre necesita fermentar para llegar a serlo: la hominización como proceso de fermentación o maduración.

30. El mar: su sedante fatalismo y su engañosa serenidad en Gil-Albert.

31. Lo oriental es indefinido y extensivo: lo occidental es definido e intensivo.

32. El Guggenheim como Caverna trasparente o Cueva posmoderna: interior exteriorizado (alétheia). 
33. Vivir con ilusión pero no de ilusión: vivir con ilusión pero no ilusamente.

34. No luz, calor: nos morimos de frío (Unamuno romántico).

35. Ante el mar indiferente (Gil-Albert): indiferente es el mar, pero no yo que difiero ante su indiferencia.

36. El aforismo me vierte afuera y adentro: me divierte y revierte.

37. Alguien molesta en el autobús dando palmas, lo miramos mal y prosigue: pero nos sonreímos de él y se acalla.

38. El conductor de la cisterna me moja, le increpo y se mofa: para chulo él.

39. Mi vida como una obra: y mi obra como una vida.

40. Diviso a los convecinos frente a mi vivienda enjaulados igual que yo: inquietos igual que yo, homínidos como yo.

41. La sensibilidad española: sensitividad.

42. Decir lo mínimo y, en ese mínimo, todo lo demás (Gil-Albert): una buena definición del aforismo.

43. Hay que elegir entre vivir la vida o plastificarla: entre la ternura y la tersura, las arrugas y el almidón.

44. La pareja en el parque: paso la primera vuelta y riñen ásperos, paso la segunda y se reconcilian fusivos: paso la tercera y se aburren distendidos.

45. Un cielo deslumbrante de luz, bajo el que se columpian los abanicos de las palmeras (T. Mann).

46. Tradicionalmente la teoría era estricta y la praxis laxa: en mi caso la teoría es abierta o avanzada y la praxis cauta o precavida.

47. Donde no hay dioses, pululan los espectros (Novalis).

48. Lo que está expresado queda despachado (Tonio Kröger).

49. No importa tanto lo que hizo Jesús exactamente sino lo que nosotros hemos hecho con él.

50. El sufrimiento y su profundidad trascendente.

51. El gozo y su altura evanescente.

52. Voluptuosamente habla un hombre vacío: Luis A. Villena.

53. Pámpano: pimpollo despampanante.

54. El origen asiático de los amerindios: de ahí su ser occidental y su noser oriental.

55. En Thomas Mann la materia trata de enamorar al espíritu: en Gil-Albert el espíritu trata de enamorar a la materia.

56. Sí, quizás lo típico español sea el encarnacionismo: la encarnadura. Lo positivo de ello está en la sensitividad, lo negativo en su exacerbación. 
57. La exacerbación: que el hígado se erija en centro y desplace a la razón (parafraseando a Gil-Albert).

58. El gran problema teológico es haber reificado a Dios: pero Dios no es realmente sino idealmente, no tiene realidad sino surrealidad, no tiene ser ni estancia porque es una instancia: la primera y última instancia.

59. Amamos lo recóndito: a través de lo visible.

60. ¿Qué traspasa mi alma? Una imagen cincelada.

61. Razón afectiva versus razón defectiva.

62. El suicidio es un abandono de sí mismo y de los demás: en su lugar abandonarse a sí mismo y a los demás (abandonarse a Dios).

63. Lo que endulza al cuerpo grosero, amarga al cuerpo sutil.

64. Gil-Albert certifica que su yo ocupa el lugar de su alma cual jaula vacía: en mi caso el yo es la jaula vacía que se diluye en el alma plenaria. Por eso para aquel el alma flota sobre la inteligencia, mientras que para mí el alma es grávida y el intelecto reflota.

65. El hispano suele vivir con inmediatez: pero yo vivo mediatamente (meditativamente).

66. Amo, leo, escribo, rezo, me aburro y como: no me aman, no me leen, no me escriben, no me responden, pero me aburren y duermen, aunque aún no me comen.

67. El amigo es el referente de la aferencia.

68. En América nada fracasa tanto como el éxito (B. Schulberg).

69. La cantante Alaska dice haber visitado el Santuario de Eleusis: pero no existe desde tiempo inmemorial (está derruido).

70. Vivir es morirse: morirse es vivir.

71. La mujer es esquiva: y el hombre casquivano.

72. Precisamente porque la vida no acaba de obtener sentido, concluye en la muerte que tampoco lo tiene; pero se trata de una conclusión lógica y, por tanto, con cierto sentido.

73. Gil-Albert tiene el alma mediterránea: yo tengo el alma cantabricona.

74. Amamos a personas que no son valiosas: precisamente porque no lo son, porque son desvalidas.

75. El hombre necesita ciertas ilusiones para sobrevivir: ilusiones constitutivas de felicidad.

76. Sufro de anhelos a menudo inatrapables (o algo así): pero no pasa nada o, mejor dicho, todo traspasa. 
77. El eros filosófico no reniega de la naturaleza sino que la sublima culturalmente: así en el Simposio socrático-platónico.

78. El interés de la mitología como pansignificatividad de lo real en Cassirer: omnisignificatividad diferenciada en la religión entre lo sagrado y lo profano.

79. Todo se resume así: calidad y caridad (inteligencia y amor).

80. El alma como síntesis o condensación del hombre: lo que reflota simbólicamente tras la muerte (nuestro precipitado existencial).

81. Lo bueno es lo que contribuye al bien-estar, dice $\mathrm{O}$. K. Bouwsma: pero lo bueno placentero no tiene ubicación por no ser sensación (sólo se ubica sensacionalmente el dolor).

82. Lo que hemos llamado nobleza de nuestro carácter es en realidad rudeza: noble rudeza.

83. Cuanto más se estrecha la vida, más intrigante se pone.

84. En alemán Kram es lo despeinado y Kamm el peine que lo peina: dualéctica.

85. Mi libido se remansa en la escritura: cambiando su color rojo en azul.

86. La infinitud del gozo: y la indefinitud del sufrimiento.

87. Dios implacable, aplácate y haz que al final de mi vida me quiera y quieran un poco, recoja algún fruto y me adentre aceptativo en el túnel sin fondo.

88. Los que en el mercado venden lo vendido y el valor (J. Zorrilla),

89. Bécquer explayándose en un mar sin playas: corriendo tras la sombra ardiente de una visión (Rima XV).

90. La visión triste y bella del sublime concierto de todo aquel horrible desconcierto, me hacía traslucir en torno de ella algo vivo rondando un algo muerto (Campoamor): la vida humana, también llamada existencia (sin consistencia).

91. En nuestra famosa Boda Principesca no logro ver (porque no lo enfocan) lo que más podría interesarme: el retablo de la Catedral de la Almudena.

92. La cola de pavo real de ciertas novias: pavesa irreal.

93. El cubismo, según C. Fuentes, sería una pintura sin espacio.

94. La adolescencia adolece de dulzura y crueldad.

95. Vivir a temporadas como un animal herido, renqueante, frágil ante las embestidas del tiempo, dejando un reguero de sangre sobre el quebradizo hielo de la vida (J. C. Llop). 
96. Lo tenemos todo: menos a nosotros mismos.

97. Amor saca amor (Teresa de Jesús).

98. La vida como lucha cruel a favor de la especie: esta afirmación de Hitler es una afirmación de los de su especie sobre el individuo y los individuos.

99. Me pareció un perro abandonado: pero al final comparecieron los dueños (menos mal).

100. La sensibilidad se colorea de todo aquello que toca: porque es recipiente.

101. El dolor molar de la vida: y el sufrimiento incisivo de la existencia.

102. El discurso cesaropapista del cardenal Rouco en la Boda Principesca: el destino único de España bajo la Iglesia.

103. Nuestras cabareteras machistas exigiendo hombría: así la hembra/hombre Sara Montiel.

104. Escribo tacos aforísticos: en su doble sentido de rollo e improperio.

105. La canción de Mikel Laboa "Baga.biga.higa" no tiene significado lógico pero tiene sentido simbólico-musical: el cantante lo musita agazapado tras la brillante orquestación de Carlos Puig.

106. Si quieres hacer algo por el mundo, no te metas en él: pero si quieres hacer algo por ti mismo sal de ti al tú.

107. La vida es una contingencia: y acaba contingentemente.

108. Al hablar me expando: al escribir me impando.

109. Los mitos no han sucedido sino que están sucediendo (Gil-Albert).

110. Detrás de la típica función sentimental se encontraría según J. Hillman la arquetipal figura de la Gran Madre: como matriz aferencial.

111. Me gusta la música de Bach: que asocio a la compacta madera de boj.

112. Contra la brusquedad de la vida: el vino Lambrusco frizzante o fricativo (de aguja).

113. Se vive mientras se ama: se pervivive mientras se es amado.

114. Hermenéutica no es Farmacéutica: por eso no da recetas (la solución mañana).

115. La gracia del amor: un don que se recibe para darlo.

116. Ni jefes ni relojes, dice una pintada: será porque nos cronometran el tiempo.

117. La Guerra de Troya comienza por el rapto de Helena por Paris, pero se continúa porque el troyano Héctor mata a Patroclo, el amado de Aquiles, que lo vengará: pero en el reciente film americano, Aquiles es Brad Pitt y no ama a Patroclo sino solamente a las mujeres. 
118. La vida, que nos promete inmortalidad, nos acaba dando muerte: inmortal.

119. Todo tiene su ventaja: la enfermedad nos hace ver lo que somos sin saberlo - mortales-.

120. La escritura como agarradero simbólico.

121. El totalitarismo es el todo que en nombre de sus partes masculinas (genitales) no asume sus partes femeninas (genéticas).

122. La revolución es la manipulación de la evolución.

123. El hombre mediterráneo como homo loquens: elocuente.

124. La traducción gil-albertiana del Fübrer como el Furioso.

125. La norma no tiene en cuenta a la excepción: considerándola anormal.

126. La vida nos apropia y expropia.

127. No vivo mal, no vivo bien: vivo como puedo.

128. Sloterdijk y la captación de atmósferas, climas y ambientes culturales: como, por ejemplo, nuestra actual cultura del vacío.

129. La cultura del vacío se basa en el vaciado cultural: en su lugar florece la presunta/presuntuosa civilización tecno.

130. Curiosamente la falta de sentido nos libera del sentido: libertad.

131. El Rector Eguíluz habría traído luz a Deusto y el Rector Ábrego cierto viento ídem: pero el Rector Oraá habría oreado nuestro campus.

132. Atacamos en el otro lo otro de nosotros mismos.

133. Empiezo a perder facultades: acabaré perdiendo hasta la facultad de filosofía.

134. La vista es el sentido del espacio, el oído del tiempo, el tacto de la sensación (exterior) y el gusto del sabor (interior): el olfato sería el sentido simbólico del sentido (el sentido de la orientación).

135. La coimplicación de los contrarios en Lyotard: Dios y perro (God y dog).

136. Los aforismos permiten trocear las vivencias y desfascinar su influencia.

137. El amor y su boomerang: entonces se invierte y topa con su revés (Roma).

138. La obligación femenina de enseñar el ombligo: la actual ombligación.

139. El sentido es el significado pleno (E. Lask): la significación axiológica.

140. En Hölderlin lo más profundo es lo más vital.

141. La naturaleza nos va quitando vida antes de abandonarla: y nos va quitando razón antes de perderla. 
142. El hombre tiene sed de hombre (humanidad).

143. Bush, Blair y Aznar: los Tres Mosqueados.

144. Sonríe sin saña: sonríe sin enseñar los dientes.

145. Si hay Dios todo es aún posible: y si no hay Dios (el) todo es imposible.

146. Me gustaría colgarme de algo, pero no hay nada que lo resista: ni una música, ni un poema, ni una plegaria, ni un amor.

147. Siempre lo mismo: y los mismos.

148. He tardado casi medio siglo en saber que no os importo nada: que puedo morirme ahora y que mañana todo sería igual (José G. Nieto).

149. El viejo esperando la enfermedad fatal: la causa mortal.

150. Entre la añoranza y el deseo: el alma consútil.

151. Según J. C. Llop, la inteligencia tendría relación con el nombre de las cosas: y la sensibilidad con los adjetivos.

152. Fallece Jesús Gil, vituperado vivo y alabado muerto: quizás representó nuestras virtudes (cierta majeza) y defectos (cierta rudeza).

153. Mi primo Jesús dice que puede entenderlo todo menos la homoerótica: Jesús qué primo.

154. A mí me pasa lo contrario que al primo Jesús: puedo entender bien la homoerótica pero apenas todo lo demás (incluido en ello mi deprimente primo primate).

155. El motín de la mirada.

156. Hubo indudablemente en este rincón extremoso de la tierra un choque demasiado brusco entre lo nórdico y lo meridional, entre lo blanco y lo negro (Gil-Albert).

157. Con los años la vida es vivida más tranquilamente: el tiempo se ha espaciado.

158. Apenas si aprendí a tocar el piano y el organillo con una mínima técnica: por eso el tocarlo me sentimentaliza decadentemente.

159. Nam, ñam dico vobis (De verdad, de verdad os digo): Así comentó Jesús ante la multitud hambrienta la multiplicación de los panes y los peces.

160 Puedes pedirle a Dios lo que necesites: pero si Dios te pide lo que necesita puede ser el diablo.

161. Encuentro mi banco solitario en el montículo: como si me estuviera esperando tiempo ha entre los árboles.

162. Soy un junguiano heterodoxo: pienso que el presunto a priori de los arquetipos es a posteriori (procede de la experiencia con los tipos y de los tipos de experiencia). 
163. Se dice que el granito del monasterio de El Escorial vivifica a vivos y muertos: pero sólo los refresca.

164. Me extraña el matrimonio: por la mutua extrañeza de sus contrayentes.

165. No hay Protorrelatos fundamentalistas ni Metarrelatos absolutos: sólo hay Interrelatos relacionales.

166. La Hermenéutica como Interrelato: contra la Razón totalitaria.

167. Hollywoodiense: Hollyputiense.

168. Lo que me ha interesado del film La pelota vasca de J. Medem es lo que nadie ha ponderado: la definición negativa de lo vasco por Orson Wells (no-es otro, no es no-vasco, quizás por no pertenecer al ser indoeuropeo).

169. Entender el no-ser vasco no política sino culturalmente a modo de vacío (uts): concavidad oteiziana, ser-no, matricialidad.

170. La vida es el ser real: la muerte es el ser realísimo.

171. Damos sentido al conjunto a costa de lo particular: damos sentido a lo particular a costa del todo.

172. Esa atmósfera de sexo tan espesa como jarabe (J. C. Llop).

173. Dios dirá: si es que habla.

174. Soy un vasco-aragonés de pro y contra: autocrítico.

175. La belleza griega, el orden romano y la anarquía cristiana: el mundo según Gil-Albert.

176. Moisés sacó agua de una roca: porque el agua promana de entre las rocas.

177. O. Wilde condenado en prisión a hacer y deshacer cuerda de esparto: Ocnos el soguero.

178. Algunos autores modernos consideran a Epicuro como una especie de franciscano: con sentido.

179. Los aforismos como autoayuda: y heteroayuda.

180. Tengo al amigo chinito a una distancia infinita: indefinida.

181. Oí triste los tangos de Gardel, y me llovían: los oí alegre, y me sobrevolaban.

182. Hay que visitar al médico cuando estemos bien y él no tanto: de lo contrario nos domina.

183. Los médicos son hoy día los dioses: odiosos.

184. El precioso rostro de Cristo de Goyo en la Capilla de la Clínica de la Virgen Blanca: trasmite tranquilidad y fortaleza. 
185. La gastroscopia no es tan mala como dicen, primero me pongo nervioso pero después aguanto fuerte: mi ridículo fue comer después con la garganta aún anestesiada un buen jamón reconvertido en insípido.

186. Me llegó al alma la compasión por mi dolencia de la humilde Montse: la empleada del hogar.

187. Hay quien ni respira: yo necesito aire.

188. Bach y las cigarras en Gil-Albert: aserrando la melodía en armonía, lo lineal en simultaneidad, lo transeunte en permanente, lo huidizo en fatalista, lo humano en lo cósmico.

189. Los que tanto hablan de Dios no le dejan hablar.

190. El buen amigo siempre está en el trasfondo: a menudo dormido.

191. El Estado como maquinación.

192. Los Apóstoles del friso de Oteiza en Aránzazu como ascetas abiertos en canal me recuerdan los retorcidos olivos cantados por Gil-Albert: «Los olivos como ascetas, secos, retorcidos y ahumados por la acción de un fuego interior y algunos abiertos en canal recordando a esas piezas de caza que asan a las parrillas luego de haberles extraído las vísceras y las entrañas» (Breviarium vitae).

193. Llamamos valientes a los que se atreven a actuar: pero no a los que se atreven a no actuar o a pensar.

194. Guiri es el nombre que dieron los carlistas a los liberales: ahora es el nombre que se da en el País Vasco a los turistas foráneos (bienvenidos sean aquellos y aquestos guiris).

195. El destino convierte el tiempo humano en espacio mítico: transhumano.

196. La desesperación late al fondo de todo mortal, según Gil-Albert, como motor oculto.

197. La heterodoxia vivifica la ortodoxia: la excepción coafirma la regla.

198. La espontaneidad española: la gestualidad italiana: la moderación francesa.

199. La religión como anhelo: de otredad radical.

200. Pensar lógicamente es pensar irrealmente.

201. Silencio acompasado.

202. La suprema belleza es el amor.

203. Si el que busca la felicidad en el amor no es un mitómano, sucumbirá al engaño (Gil-Albert).

204. Quizás la realidad más real sea la dolorosa: la realidad final de la enfermedad y la muerte (lo demás sería irreal o irrelevante). 
205. Si en la cultura no eres mitólogo, acabarás dogmatizando.

206. Si en la vida no eres un simbólogo, acabarás reduciéndola.

207. No he encontrado habitáculo en este mundo: sólo encontraré una fosa donde fosar (si no me ahuman).

208. Empiezan a rebelárseme algunos órganos corporales: la corporación peligra.

209. También la vejez forma parte de la vida y, por lo tanto, forma.

210. Conformación: configuración: coimplicación: símbolos de la arquitectura del alma.

211. El alma es tiempo condensado: espacio interiorizado.

212. Según Gil-Albert, Tiziano pinta la materia y Velázquez la existencia: existencia que trasparenta su sombra interior, el aire ciego, el trasfondo.

213. Toda eliminación se expía, dice Gil-Albert: porque no es pía.

214. El amor como vino espumoso que acaba espumado: esfumado.

215. No puedo amarle porque le amo demasiado.

216. Conviene dejar algún correo electrónico en el ordenador: para que nos acompañe virtualmente.

217. Sí, la muerte introduce en la existencia la zozobra, el aguijón, la vida.

218. La aforística como sedimentación de la vida.

219. Acumulo aforismos para mí mismo: así exonero mi alma, articulo la vida y dejo un rastro de sentido.

220. Cultivar el alma: respetar el espíritu: cuidar el cuerpo.

221. Los creyentes no son buenos: quizás serían peores si no creyesen.

222. De viejo todo es aviejado: de joven todo es crudo.

223. La madurez es un camino hacia la perplejidad (Gil-Albert).

224. En el aforismo acotamos la clave de lo transitivo o transeúnte en su meollo: salvaguardándolo.

225. La lógica musical: articulatoria y relacional (coimplicacional).

226. Cuidado con la profundidad profusa: podemos anegarnos.

227. Cuando los dioses nos abandonan siempre hay algún demonio solícito (Gil-Albert).

228. La racionalidad retórica como razón intersubjetiva, comunicativa o participativa de carácter argumentativo y persuasivo: en la que los participantes se dan las reglas de juego contingente y democráticamente. Pero también corresponsable o cómplicemente de acuerdo a la mutua trascendencia inmanente del otro. De esta guisa, la verdad trascendente 
se trasforma en trascendencia inmanente como verdad-sentido: en donde el sentido ya no está sujeto a mero consenso abstracto sino a consentimiento interpersonal.

229. El consenso es de alguien sobre algo: el consentimiento es de alguien sobre alguien.

230. Cuanto más perseguimos el sentido a lo largo de la vida más se oscurece: porque el sentido de la vida se embosca en la muerte.

231. En la vida he amado a gente necesitada: necesitada como yo de amor.

232. Resignarse es signarse doblemente, así pues persignarse.

233. La persignación como símbolo de coimplicación: arriba y abajo, a derecha e izquierda.

234. Vivimos de cápsulas y cláusulas: y algunas pandectas.

235. El lema de algunos: hoy no trabajo, mañana sí.

236. Me estoy mirando el estómago: pero no el ombligo (nobleza obliga).

237. Hay amistades que son como un destino: aunque quisiera no podría sustraerme, pero además ni puedo ni quiero.

238. Todo y nada parientes de lo mismo.

239. Mis problemas con el estómago: no sé si son físicos, psíquicos o morales (epicúreos).

240. Autocrítica del pensamiento débil: asumir la debilidad es ya fortaleza.

241. La barba griega fue al principio signo de cierta feminidad entre los romanos.

242. El gusto es significativo de la mentalidad (Gil-Albert).

243. Gil-Albert perdido en el mundo, flotando en el aire, desasistido excepto por un sí mismo evanescente: el arquetipo del poeta no abstraído sino absorbido, no abstracto sino absorto en el fluir del ser.

244. La dehiscencia del ser: su brotar cuasi taoísta.

245. Extraer la felicidad de la desesperación (Gil-Albert): porque ya no hay nada que perder sino perderse.

246. La pintura posmoderna de Susana Talayero ofrece un espectáculo sombrío en medio de la exuberancia, de modo que el experto Javier González de Durana ha podido hablar de sus imágenes como "heridas interiores». Heridas anímicas, matizaría yo, ya que aquí el alma comparece zaherida como una sombra, reprimida como la sangre, cautiva como una jaula, enmarañada como una burbuja inhibida. Yo pienso que la pintora ofrece una visión autocrítica de nuestra alma como actual sombra del cuerpo: por eso proyecta un espacio temporalizado, una vida 
agusanada, formas informes, colores endoloridos, luz sombreada, entusiasmo agarrotado, realidad turbia... Al respecto concitaría al poeta Juan Gil-Albert que, en su Breviario de vida, dice algo muy pertinente: "La vida viene a ser algo así como lo que debe sentir un pájaro cuando, inopinadamente, es trasladado, en su jaula, de un lugar a otro: una mezcla indescifrable de temor y anhelo" (Breviarium vitae, II). Pues bien, nuestra autora, que es joven y jovial, no ha reprimido el lado oscuro de la vida humana - el temor-, pero tampoco el lado cromático -el anhelo-. Por mi parte, yo representaría el temor por esa especie de larvas o gusanos que pueblan sus pinturas desasosegadamente, mientras que el anhelo estaría expresado por ese color lascivo que remite al modernismo y a los felicitarios años veinte compulsivamente. $\mathrm{O}$ la vida como color sobre negro o negro sobre color.

247. Pero la oscuridad está por todo lugar abierta, envolviendo la misma luz y más omnipotente que ella (Gil-Albert).

248. A través de nuestra propia familia nos resultan familiares los demás.

249. La verdad se descubre, el sentido se recubre: por eso aquella se encuentra y fija, este se sonsaca y proyecta.

250. Conviene confesar nuestros pecados inconfesables

251. No soy sabio porque soy precipitado: tengo un precipitado de sabiduría (aforística).

252. Algunos se atienen al placer como a un deber: otros se atienen al deber como a un placer.

253. Finalmente el hombre tiene que asumir su sino, su sí y no: más allá de sí mismo quedan los otros, y más acá la otredad radical.

254. Voy abrigado: porque tengo algo que abrigar.

255. En Comillas me llamaban el manta: pero me revertí en el clámide.

256. Apertura versus apretura.

257. También los pensamientos son afecciones: por eso nos afectan.

258. Tanquam passer solitarius in tecto (Salmo): Como un pájaro solitario en la techumbre.

259. En Velázquez los cuerpos flotan en el éter.

260. La cultura como fuerza complementaria de la energía animal: como una modalidad de vida más alta (Gil-Albert).

261. Ahora por lo visto todo es mito o invención.

262. El español no ha sido comedido porque estaba recomido: el francés es comedido porque está bien comido. 
263. En España la vida superficial es estupenda: otra es la vida profunda (si la hay).

264. Brota de la fuente de los placeres un dejo amargo (Lucrecio).

265. Aragón, bronco y cordial (Gil-Albert): broncordial.

266. El realismo español ha sido pobreza: y el idealismo escape.

267. La vida es joyante y joyosa: un brillo mortecino.

268. La metáfora como artilugio de caza para matar dos pájaros de un tiro (Gil-Albert): y el símbolo como artilugio para casar dos pájaros de una contuición.

269. Para algunos el pecado está en no pecar: es el pecado como peccato (lástima).

270. La imagen de la muerte como un centrifugado en T. Mann: centrifugación final.

271. La proyección del chivo expiatorio: el complejo encabronizante (en la excelente traducción de A. Álvarez Bolado).

272. En San Agustín el amor es el peso/poso de nuestra alma y su gravitación: pondus meum, amor meus.

273. Vivo junto a un parque visitado por niños: menos mal.

274. El tiempo pasa: por eso hace pasar lo bueno y también lo malo.

275. Según Gil-Albert, el español no es capaz de digerir la realidad tal como es: por eso la exacerba, insatisfecho, a su desvarío.

276. Me gusta en el catolicismo su deje pagano, folklórico y sentimental: pero sin estridencias.

277. En Rembrandt hay esa oscuridad que cobija la luz: en Vermeer hay esa luz que cobija la oscuridad.

278. El/lo débil nos debilita: compasivamente.

279. Dios no sería tal para sí mismo: sólo lo es para el Hombre.

280. El animal no lo es para sí mismo: tampoco el animal humano lo es para el hombre.

281. El español: rudo y sensitivo.

282. No permanece culturalmente la mera materia como quiere Ronsard, ni permanecen las puras formas como quiere Gil-Albert: queda la complicidad de la materia y de la forma cuyo símbolo es el aforismo.

283. El sentido de la vida se quiebra al morir: pero se recupera en la muerte como cosentido (requies, descanso eterno).

284. La nada es simbólica: porque está acompañada del ser ya sido, que es o por ser. 
285. Me gusta mi nombre sueco de Anders: porque significa diferente.

286. Mi vesícula tiene pólipos: se trata de una vexícula.

287. El colmo de la música es que moleste.

288. En el relacionismo radical (sustancial o esencial) de Eckhart, Dios es Ser (Deus est esse) y Ser es Dios (esse est Deus): puede consultarse M. P. Schirpenbach (Wirklichkeit als Beziehung).

289. La tradición de Francia es tener muchas tradiciones, dice Ortega: retenerlas todas coimplicadamente.

290. La muerte no explica nada, pero lo resume todo (Gil-Albert).

291. Dios es la vida y la muerte: Cristo.

292. La voz empastada de Mikel Laboa: y sus cantos colgados tenuemente.

293. En El Greco se da la coimplicación de lo sensible y lo suprasensible.

294. El lenguaje ni copia lo real ni lo crea: lo concrea.

295. La verdad suele ser aquello con que no contábamos, dice Gil-Albert: porque la verdad tampoco cuenta con nosotros.

296. La verdad que cuenta con nosotros: la verdad-sentido.

297. La estatuaria griega es genérica y abstracta o trasparente.

298. La vida es un punto de partida y no de llegada: la existencia es un camino y no una posada.

299. El alma es proteica y esponjosa: arácnida y seductora.

300. Tomás Moro y su utopía contra la riqueza: utopía católica pero no anglicana, es decir, medievalizante pero no moderna.

301. Demente como el mar encrespado (Shakespeare).

302. Estoy viejo: esperando la mano de nieve que me deje helado.

303. Si el secreto de la vida no estará más en el ir que en el llegar (Gil-Albert).

304. Pensar es reflotar las cosas: para su asimilación.

305. El norte responde al frío con racionalidad: el sur responde al calor con color.

306. Hacer de tripas corazón: hacer de la vida (animal) existencia (humana).

307. Lo distinto y su distinción: lo distinguido.

308. Fuera de la medida del hombre nada hay que sepamos (Gil-Albert).

309. El placer es genérico o general: el gozo es específico o íntimo.

310. Proust o la antiaforística: prolijidad.

311. El aforismo es conciso: circunciso.

312. Un producto fabril: un producto febril. 
313. La verdad oscura: la aceptación viril de nuestro duro destino en brazos de nuestras flaquezas (Gil-Albert).

314. La aforística como lenguaje cuasi litúrgico.

315. Una cosa es la razón humana y otra distinta la razón del hombre.

316. En Deusto desaparecerá antes la filosofía que la teología: en este país es posible lo divino sin lo humano.

317. Copiemos a Europa: porque si nos copiamos a nosotros mismos estamos copados.

318. Sin un cierto sadomasoquismo no se puede vivir: pero de un cierto sadomasoquismo se puede morir.

319. No se vive si no se sabe (B. Gracián): no se come si no se saborea.

320. La imaginación es recreadora: el pensamiento es conservador.

321. La realidad resulta humana por su sentido o sinsentido.

322. El saber descansa (Gil-Albert): descansa pero rumia.

323. El auténtico pensar autentifica: porque nos hace ser nosotros mismos abiertamente.

324. Un país infantil: digo que soy sexagenario y todos me recitan la consabida cantinela de que eso no es edad.

325. Encontrar en otros un paralelo humano refuerza y descansa.

326. El hombre llega al final más solo, más enfermo y más desvalido.

327. La lagartija eléctrica: y el sapo estático.

328. El amor como embarazo: de otredad.

329. Simbolizar es insuflar alma: animar, alentar, exhalar (crear).

330. No me he arrugado a partir de los sesenta años: me he acurrucado.

331. También a mí me harán un homenaje tras quedarme yerto: después de la reyerta con la muerte.

332. El corazón es el que pondera según san Agustín: ponderoso caballero es el amor.

333. La desmesura del existir en Heidegger: así lo ve M. Galcerán inspirándose en K. Jaspers.

334. La delicuescente escena china con su cromatismo, sus dragoncetes, las sedas y el bambú, los motivos vegetales y el agua.

335. Aquí estuvimos: pero no estaremos.

336. Los alumnos recitan lo que el profesor cita.

337. Me compadezco de mí mismo.

338. Hablar es romper aguas: dar a luz (emerger).

339. Todo es fantasía, más cercana o más lejana (Kafka). 
340. Yo soy todos: todos son yo.

341. Nos llevamos con nosotros el alma que nos sobrevuela: pero dejamos aquí su sombra - la escritura-.

342. El aforismo es lentamente rápido: el resplandor en las tinieblas.

343. No me gusta la poesía de Jorge Guillén: porque las cosas están ahí en una claridad bobalicona (sin alrededores). 